\title{
Pattern of recruitment variability in the geographical range of the exploited northeast Atlantic fish species
}

\author{
Thomas Brunel*, and Jean Boucher \\ Département Sciences et Technologies Halieutiques IFREMER, Centre de Brest, BP 70, 29280 Plouzané, France \\ *: Corresponding author : thomas.brunel@libertysurf.fr
}

\begin{abstract}
It has long been argued that populations living on the edges of the species geographical range should exhibit stronger environmentally imposed variations in abundances than populations living near the centre of this range. This so-called 'Species Range Hypothesis' is tested here for the recruitment of 62 marine fish populations of the northeast Atlantic, belonging to 17 species. The pattern of increasing recruitment variability from the centre towards the edges of the species range was modelled by a quadratic linear regression between an index of interannual variability in recruitment and an index of population position in species range. The relationship between recruitment variability and exploitation rate was also investigated.
\end{abstract}

A wide range of recruitment variability was observed among the 62 populations. The expected latitudinal pattern of recruitment variability was significant when populations of the various species were pooled in the same analysis. At the species level, this pattern was found for most species, but was significant only for cod and sole. Recruitment variability was also dependent on the number of years in the time series, although this association did not perturb the relationship with population position. The analysis did not show any clear impact of fishing on recruitment variability. These results suggest that the influence of environment on the recruitment of fish populations is stronger for populations living on the edges of the species geographical range than for populations living at the centre of this range.

Keywords: Recruitment variability; Species range hypothesis; Northeast Atlantic; Comparative approach; Environment 


\section{Introduction}

Understanding the mechanisms responsible for recruitment variability of marine fish populations remains one of the most important issues in fisheries ecology. For heavily exploited populations, mostly composed of young year classes, variations in recruitment have a crucial influence on population dynamics. Current stock management procedures consist in limiting exploitation to maintain stock levels above 'safe biological limits' defined by population models as the minimum stock level that allows sufficient recruitment. However, a question that remains unresolved is how the assumed stock-recruitment relationship used in these models is affected by how a variable environment influences the success of fish reproduction. For instance, high recruitments were observed for gadoid species in the North Sea during the late 1960 s and 1970s, when stock levels were not particularly high. This socalled 'gadoid outburst' has been ascribed to a favourable prey environment for larval survival (Cushing, 1984; Brander, 1992; Beaugrand et al., 2003).

Research on recruitment-environment relationships has mainly focused on recruitment determinism, with the aim of disentangling the various processes that link year-class strength to environmental factors. Great attention has been paid to growth and survival during early life stages, when year-class strength is supposed to be determined (Hjort's (1914) critical period hypothesis). Environment can influence larval survival through its control of food availability (Cushing's (1982, 1990) match-mismatch hypothesis; Lasker's (1975) ocean stability hypothesis) and of transport and retention mechanisms (Sinclair's (1988) member vagrant hypothesis; optimal environmental window of Cury and Roy (1989); Bakun's (1996) ocean triad). Environmental factors also have a direct effect on vital rates, as has temperature (Pepin, 1991; Brander, 1995).

Relationships between environment and fish stock recruitment have generally been investigated by searching for correlations between recruitment time series and a set of 
physical factors. Such empirical correlations have been found for many populations (see for instance review in Shepherd et al. (1984) but few of them stand when retested with more recent data (Myers, 1998). This highlights the fact that recruitment results from various mechanisms, each of them possibly influenced by different factors that can interact and change over time. Other approaches have attempted to show environmental influence as a whole, without trying to break down the effects of different factors on recruitment processes. For instance, comparisons of recruitment dynamics have shown the existence of synchronous variations among groups of populations, suggesting an effect of common environmental factors on recruitment (Garrod and Colebrook, 1978; Koslow, 1984).

The goal of the approach developed here is to test the 'species range hypothesis' (SRH) according to which populations living on the northern and southern edges of species distribution should be more influenced by the fluctuations in the environment than populations living near the centre (Huffaker and Messenger, 1964; Richards and Southwood, 1968; Coulson and Whittaker, 1978). On the distribution borders, environmental factors more frequently reach values that are barely suitable for the species. Populations located at the edge of the species range are less adapted to the environmental conditions they experience, and are more likely to be susceptible to density-independent factors. These populations must therefore be more variable than those located at the centre of the range (Gaston, 1990). For fish populations, interannual variations in recruit numbers result from environmental fluctuations (temperature, winds, currents), and the magnitude of variability reflects the strength of the environmental stress. The pattern of increasing recruitment variability from the centre towards the edges of marine fish species distribution is hence investigated here.

Myers (2001) showed in an analysis on 700 populations that recruitment variability increases at low stock levels. Recently, Brander (2005) provided evidence that cod recruitment is more affected by environmental variability when stock biomass is low. Thus, by 
reducing the parent stock biomass fishing can increase the variability in recruitment, and heavily exploited populations should exhibit a more variable recruitment than others. This effect of fishing, which is likely to disturb the relationship between recruitment variability and population position in the species range, is also investigated here.

Many advances in recruitment research were made by adopting comparative approaches. These approaches are based on the idea that the range of variation of environmental factors experienced by a given population is generally too small to show a significant influence of these factors on recruitment. Pooling data of a great number of populations in the same analysis is a way to increase the range of environmental conditions experienced and to make it possible to detect their influence on recruitment (Brander, 2000). It also permits statistical tests to be performed with an increased number of degrees of freedom. Such comparative approaches have already been used to test the SRH for marine fish recruitment. The meta-analysis of Myers (1991) based on recruitment data of 53 populations of Atlantic cod, haddock and herring showed that recruitment variability was greater at the limits of the species range than at the centre. Leggett and Frank (1997) and Philippart et al. (1998) addressed the same question for populations of northwestern Europe at the single species level, but did not find the expected latitudinal pattern of recruitment variability. Here, the SRH is tested in a multispecific analysis, at the geographic scale of the northeastern Atlantic, for populations of the main commercial fish species. 


\section{Material and methods}

\subsection{Recruitment variability}

Recruitment data were collected from ICES ACFM reports, available on the ICES website (http://www.ices.dk/iceswork/acfm.asp). For each fish stock, population numbers at age are calculated by cohort analysis methods from commercial catches at age and research survey abundance indices. Populations with time series of less than 10 years were not included, as it was not possible to correctly assess their recruitment variability. Stocks whose distribution cover the whole species range (e.g. blue whiting) were also excluded. The 62 populations of 17 species suited for our study are distributed over the northrastern Atlantic, from the Strait of Gibraltar $\left(36^{\circ} \mathrm{N}\right)$ to Spitzbergen $\left(80^{\circ} \mathrm{N}\right)$. They are listed in Appendix 1.

The relationship between a population's recruitment variability and its geographical position within the species range was investigated by using the high frequency component of recruitment variability. High-frequency - interannual - variations of recruit numbers occur too fast to be caused by parent stock fluctuations, and hence are more likely to result from the influence of interannual variations of the environment (Garrod and Colebrook, 1978; Shepherd et al., 1984). In contrast, low-frequency recruitment variations - or trends - can be related with the impact of fishing on spawning biomass (Myers and Barrowman, 1996; Cook et al., 1997), and with long-term climatic variations (Cushing, 1982; Dickson and Brander, 1993; Alheit and Hagen, 1997; Klyashtorin, 1998; Beamish et al., 2000; Buch et al., 2002). The aim of focusing on high-frequency variability is to test for differences in population responses to interannual environment fluctuations, according to differences in the mean conditions that are met by the populations at different locations of the species range. 
High-frequency variability was defined as the mean of the squared difference between log-transformed recruitment of successive years, expressed as follows:

$$
\operatorname{var} R=\frac{\sum_{i=y}^{y+n-2}\left(\log R_{i+1}-\log R_{i}\right)^{2}}{n-1}
$$

where $n$ is time series length, $y$ the year of the beginning of the series, and $R_{i}$ the number of recruits produced during year $i$. Log-transformation of recruit numbers was applied to standardise the recruitment levels of the various populations. It is besides a way to lessen the influence of strong year classes. This measure of recruitment variability refers to the first differencing transformation (taking for annual value of the series $\log R_{i}-\log R_{i-1}$ instead of $\log R_{i}$ ) that is commonly used to remove autocorrelations and conserve only the highfrequency component of the variability (Pyper and Peterman, 1998).

\subsection{Position in species range}

Data on species distribution were collected from Whitehead et al. (1989). As species distributions on the northeastern border of the Atlantic Ocean have mainly north - south extensions, population position was expressed by the mean latitude of the ICES divisions where it is assessed. Fig. 1a gives the latitudinal extension of the distribution areas for the 7 main species (light grey bands). For each species, vertical lines represent the latitudinal positions of the populations, and the part of the species range covered by the ICES data is indicated by the dark grey bands.

The ranges of the 17 species considered here have different positions and sizes, and for each species the data covered only partially the species range (Fig. 1a). In order to have a common measure of population positions for all the species, a standardised index of population position in species range (pos) was defined. It refers to the distance in latitude 
between population position (lat $\left.t_{p o p}\right)$ and the centre of the species range, with respect to the size of the range. The latitude of the centre of the specie range (lat $\left.t_{c e n t r e}\right)$ was defined by the mean of the latitude of the northern and southern borders $\left(l a t_{N}\right.$ and $\left.l a t_{S}\right)$. The position index varies from -1 to +1 (for southern and northern limits of distribution). It is null for the centre of the range and for each population it is calculated as follows:

$$
\text { pos }=\frac{(\text { lat pop }- \text { lat centre })}{0.5 \times(\text { lat } N-\text { lat } s)}
$$

Fig. $1 \mathrm{~b}$ shows the position of the 62 populations in the standardised species range. Data on population positions and recruitment variability are given in Appendix 1.

\subsection{Statistical analysis}

The increase in recruitment variability with distance of the populations to the centre of species range was tested by fitting a quadratic linear regression between high-frequency variability and standardised position index, i.e.:

$$
\operatorname{varR}=\beta_{1} \operatorname{pos}^{2}+\beta_{2} p o s+\gamma \quad(\text { model } 1)
$$

Estimates of recruitment variability may be dependent on the length of time series used (Myers, 1991). To ensure that the relationship between recruitment variability and population position in species range is not an artefact of an influence of time series length, a second model was also fitted:

$$
\operatorname{varR}=\alpha \text { TSlength }+\beta_{1} \text { pos }^{2}+\beta_{2} \text { pos }+\gamma
$$

where TSlength is the number of years of data for each time series.

Validation of the hypothesis of greater variability for populations on the distribution borders requires that: (1) the regression curve is $U$ shaped (i.e. $\beta_{1}>0$ ), and (2) lowest variability occurs at the centre of the standardised range (i.e. $-\beta_{2} / 2 \beta_{1}=0$ ). The shape of this 
expected relationship for both single and multi-species analysis is schematised in Fig. 1, with the solid part of the line representing the part of the curve where the model can be fitted from the data.

Myers (1991) tested the SRH with a meta-analytical approach. The quadratic regression between recruitment variability and population positions in latitude was performed for each of the three species and the test at the interspecies level was a combined probabilities test (Fisher, 1954). In the present work, population positions in the regression were expressed with the standardised index, in order to test the hypothesis with reference to the species distribution, and not only to the absolute latitude. This was also done in order to fit a single regression for the pooled 62 populations, which makes it possible to include in the analysis species that are represented by a single or two populations (such as sardine, anchovy, hake).

The position index, however, is potentially biased by interannual variations in species distribution. The sensitivity of the results of model 1 to different degrees of uncertainty on the position index $( \pm 0.05, \pm 0.1$ and \pm 0.2$)$ was hence tested. For each level of uncertainty, 1000 position index datasets were generated by adding a random error term varying uniformly (for instance from -0.05 to +0.05 for the \pm 0.05 uncertainty level) to the original position index. For each simulated dataset, model 1 was fitted and the distribution of the 1000 probabilities of the Student tests of significance of $\beta_{1}$ was analysed.

As linear regression assumes normally distributed variables, and imposes a rigid shape for the relationship, a non-parametric test was computed to see the robustness of the results. The Spearman rank correlation between recruitment variability and absolute value of position index was chosen to test a monotonic, rather than determinist, relationship.

The effect of fishing pressure was investigated by testing for a relation between recruitment variability and exploitation rate. Exploitation rate refers to the percentage of the total mortality that is ascribed to exploitation, and is a good indicator of fishing pressure 
(Rochet and Trenkel, 2003). For each population, the time series of exploitation rate was calculated from natural and fishing mortality data given in the ICES ACFM reports.

\section{Results}

\subsection{Recruitment variability}

A wide range of recruitment variability is found among populations (Fig. 2). For most populations, variability ranges between 0.004 (for the southern stock of hake) and 0.20 . Six populations have an extremely high variability, up to 0.427 for Norwegian herring and west of Scotland haddock. Differences in recruitment variability were also pronounced between populations of the same species. The range of recruitment variability was relatively similar among species: from 0.007 in the Bay of Biscay to 0.250 in the North Sea for sole, or from 0.019 in the eastern Baltic Sea to 0.181 in the Celtic Sea for cod. The range of variability for haddock populations was, however, remarkably higher than for other species: from 0.108 to 0.427 .

High-frequency recruitment variability appeared to be correlated to the length of time series (Pearson correlation coefficient $r=0.47, p<0.001$ ). This relationship was mostly due to several very long and highly variable time series, such as Norwegian herring and haddock in the Arctic ( $r=0.23, p<0.05$, when these two populations were removed).

\subsection{Patterns in the ranges of species}

Fig. 3 gives the relationship between recruitment variability and population position in species range for the parametric tests with the 62 populations pooled. Regression statistics and 
non-parametric test are given in Table 1 . The increase in recruitment variability toward the limits of the species range is attested by the parametric test. In both models 1 and model 2 , the second order parameter, $\beta_{l}$, is positive and significant, and the minimum of variability occurs near the range centre ( $\beta_{2}$ null and non-significant). Excluding outlying haddock populations improves the strength of the relationship $\left(R^{2}=0.27\right.$ vs. $R^{2}=0.14$ in model 1$)$. The addition of TSlength as a linear term in model 2 increases the percentage of variance explained $\left(R^{2}=0.23\right.$ and $R^{2}=0.34$ ). The non-parametric test confirms the increase in recruitment variability on the range borders, with a Spearman correlation of $r_{s}=0.52(\mathrm{p}<0.05)$ when haddock is not included and of $r_{s}=0.27$ (not significant) for the 62 populations.

For uncertainty levels on the position index of \pm 0.05 and \pm 0.1 , the probability of the Student test associated to $\beta_{l}$ in the 1000 simulated datasets is always smaller than 0.05 when model 1 is fitted on the 62 populations (Fig. 4). It is even smaller than 0.01 when haddock populations are excluded. The parameter $\beta_{l}$ is also still significant at the $5 \%$ level for uncertainty on the position index of \pm 0.2 when haddock populations are removed. For this level of uncertainty, however, the probability associated to $\beta_{l}$ is often higher than $5 \%$ for the analysis on all populations.

At the species level, the test of the hypothesis is significant only for cod, herring and sole populations (Table 2). The expected pattern of recruitment variability throughout the species range is observed for cod populations (Fig. 5a), and significant for both parametric and non-parametric tests. The regression curve for herring (Fig. 5c) also exhibits a significant concavity $\left(\beta_{1}=0.27, \mathrm{p}<0.01\right)$, but the minimum of variability occurs significantly south of the centre of species range $\left(-\beta_{2} / 2 \beta_{1}=-0.31, \mathrm{p}<0.01\right)$. For sole populations (Fig. $\left.5 \mathrm{f}\right)$, the quadratic regression is not significant but the increase of recruitment variability toward the limits of the range is patent and significant for the northern part of the species distribution $\left(r_{s}\right.$ $=0.79, \mathrm{p}<0.01)$. For other species, the null hypothesis cannot be rejected from the tests. For 
plaice (Fig. 5d), saithe (Fig. 5e) and whiting (Fig. 5g), differences in recruitment variability between populations are weak, and do not show a clear pattern with position in species range. For haddock, the pattern of recruitment variability (Fig. 5b) is clearly inconsistent with the hypothesis. The highest variability is found for populations located near the centre of the distribution range (North Sea and west of Scotland).

No link was observed between recruitment variability and exploitation rate. The influence of exploitation is significant neither for the 62 populations pooled (Pearson correlation $r=0.054, p=0.68$ ) nor at the single species level.

\section{Discussion}

For marine fish species, the $\mathrm{SRH}$, and the resulting relationship between recruitment variability and population position in the species range, was first proposed by Miller et al. (1991). The present work strongly supports this hypothesis for a variety of fish species at the geographical scale of the northeastern Atlantic. These results corroborate those of Myers (1991) and show that the relationship stands with time series longer than one decade and including more species. Moreover, the latitudinal pattern of recruitment variability is tested here using an index of population position in species range, which enables us to take species biogeography into account. This was not the case in previous studies, where position was expressed in absolute latitude. The relationship is significant only when species are pooled together in the analysis. This highlights the interest of testing general ecological hypotheses such as the SRH by means of comparative approaches. The quadratic model, however, explains only a small part of the variance in the data, even when outliers are removed. The analysis indicates that population position in species range is determinant for recruitment variability, but the high variability not explained by this pattern suggests that other factors have also an influence. 
At the species level, the lack of data to cover the whole distribution range of the species is the main cause of non-validation of the hypothesis, as was the case in Leggett and Frank (1997) and Philippart et al. (1998). The increase in recruitment variability on the distribution borders is significant only for cod populations and, in a less obvious way, for herring. For this latter species, the minimum recruitment variability occurs south of the range centre. For other species, the data cover only partially the species range. However, the relationship observed in the northern half of the range for sole is consistent with the hypothesis, even though there are no data available to confirm the relationship in the southern part. Low variability observed among plaice populations can be related to their central position in the species distribution. Recruitment variability of Barents Sea plaice, calculated from the data published by Kovtsova and Boitsov (1995), is 0.190, which suggests a high variability for the northernmost plaice population. The only species for which the pattern of variability is inconsistent with the hypothesis is haddock. North Sea and west of Scotland populations, located close to the centre of the species distribution, exhibit the highest variability. The higher variability for this species has already been noticed (Garrod and Colebrook, 1978; Hennemuth et al., 1980; Fogarty et al., 2001) but clear explanations have not been given.

The absence of a relation at the species level has been attributed to the incertitude of estimates on recruitment variability (Philippart et al., 1998). Estimates of recruit abundance from cohort analysis methods were used because they provide the most homogenous and complete source of data. These methods are, however, subject to biases arising from the uncertainty of biological parameters, such as natural mortality or age estimation, and misreporting of catches. Misspecification of natural mortality can cause spurious trends in recruitment time series (Lapointe et al., 1989), but as trends were removed in the highfrequency variability, this bias is not affecting our results. Misreporting of catches influences 
the absolute value of recruitment but does not change the variability (Restrepo et al., 1991).

On the other hand, ageing errors can lead to underestimates in recruitment variability (Bradford, 1991). Despite these possible biases in the estimates, the relationship with population position in the species range is significant. We can reasonably assume that few populations are affected by strong ageing problems.

An alternate source of data was the estimates of recruit abundance provided by scientific vessel surveys. These data are, however, affected by substantial measurement errors, and provide much more variable recruit abundance estimates (Pennington and Stromme, 1998; Hjellvik et al., 2002). For instance, estimates from the International Bottom Trawl Survey (IBTS) for cod, haddock, herring, Norway pout and whiting were compared with cohort analysis data. This survey has been carried out annually in the North Sea since 1965 and was particularly designed to give abundance estimates for young fishes. Recruitment variations in these two types of data sets are coherent for the five species (Pearson correlation coefficients $r=0.45$ for whiting and $r>0.65$ for others). Recruitment variability in IBTS data is, however, between 70 and 120\% higher than in cohort analysis data, except for herring (15\%). Furthermore, measurement errors differ between surveys, due to differences in sampling intensity, methods, gear or research vessel (Trenkel et al., 2004). Estimates of recruitment variability for populations assessed by different surveys may hence be affected by different sampling variability, which can contribute to disturbing the relationship with population position related to the SRH. For instance, the SRH tested for cod and sole with survey data was not significant (model 1: $R^{2}=0.60$, but $\beta_{l}<0$ for $\operatorname{cod}$ and $R^{2}=0.14$ for sole; $r_{s}$ not significant for both species), whereas it was with cohort analysis data. Survey data are then less homogenous, provide more variable and shorter time series than data based on commercial catches, and were not included in the present analysis to test the SRH. 
Another problem in testing the SRH could have been the differences in time series length among populations. As pointed out by Myers (1991), because of the presence of substantial long-term trends, the estimates of recruitment variability are greater when longer time series are used. In the present case, long-term trends were removed, but a positive association was still observed between varR and TSlength. This relationship can be explained by the fact that high-frequency recruitment variability is highly dependent on the number of extreme year classes occurring in the series, which increases with the length of time series. However, the relationship between recruitment variability and the position in the species range found here cannot be an artefact of this association with the number of years in the series. Models 1 and 2 give similar results, supporting the SRH, which indicates that this bias has little influence on the results.

The present study develops a new index of a standardised measure of population position in the species range. This index, however, may be biased by the changes in species biogeography that result from temperature increase caused by global warming. The warming of seawater is for instance responsible for a northward shift of $10^{\circ}$ in latitude of distribution ranges for warm water copepod species in the northern Atlantic (Beaugrand et al., 2002) and of $2^{\circ}$ for zooplankton and intertidal organisms in the western English Channel (Southward et al., 1995). Fishes have probably also moved their ranges northwards in response to regional sea warming, as suggested by the increasing occurrence of southern subtropical species in the Bay of Biscay (Quero et al., 1998) and in southwestern England (Stebbing et al., 2002). The $10^{\circ}$ shift $(1100 \mathrm{~km})$ for copepods is, however, an extreme case of biogeographical change in comparison to the average shift of $6.1 \mathrm{~km}$ per decade found by Parmesan and Yohe (2003) for 1700 terrestrial and aquatic species. Arguments for such distribution changes for the commercial fish species of the present study are moreover limited to observations of an increase of southern species in the commercial landings (Brander et al., 2003) and in scientific 
survey catches (Poulard and Blanchard, 2004). Even in making a hypothesis of strong biogeographical shift for these populations, with a $5^{\circ}$ northward shift, the average amplitude of the change in the position index is 0.13 . The sensitivity analysis shows that the uncertainty on the position index with regard to recruitment variability towards the range borders is \pm 0.1 . When the outliers are removed the uncertainty is \pm 0.2 . Although the position index may be biased by changes in species distribution, this bias is probably at present too weak to cast doubt on the results of the test of the SRH.

Exploitation by fishing was also suspected to increase the variability in recruitment. The depletion of stock size reduces the regulating density-dependent mortality of juveniles and hence makes recruitment more variable (Myers, 2001). Moreover, fishing targets the older fishes and changes the age structure of populations. Exploited populations, with lower spawner mean age and age diversity, may spawn in a reduced area and during a shorter season, increasing the risk of mismatch between larvae and suitable food production (Lambert, 1990; Marteinsdottir and Thorarinsson, 1998). This can explain the increased sensitivity of recruitment to environmental factors (Brander, 2005) and higher recruitment variability (Myers, 2001) observed at low stock levels. Thus, more heavily exploited populations should have exhibited a more variable recruitment than less heavily exploited ones. This was not the case in our study, where recruitment variability was not related to exploitation rate. This may indicate that natural differences in recruitment variability between populations, related to their biogeographical position, are more important than differences caused by fishing.

\section{Conclusions}

This study highlights the interest for fisheries ecology to adopt a macro-ecological point of view to investigate fish-environment relationships. The relationship between the 
position of populations in the geographical distribution ranges of species and the variability in their recruitment is weak, but significant and robust. This pattern appears to be little perturbed by other factors, such as time series length or fishing influence. Latitudinal position in species range is a good proxy of population adaptation to its local environment, and to its tolerance to climate fluctuations. Taking species biogeography into account may provide information on the possible impact of climate change. Populations at the southern limit of the actual species geographical range could be expected to become more and more unstable, whereas populations at the northern limit become less variable.

\section{Acknowledgements}

The authors would like to thank Mrs. F. Blanchard, S. Fifas, J.-M. Fromentin, P. Lorance, B. Planque (IFREMER), E. Chassot (AGRO-CAMPUS Rennes) and three anonymous referees for providing constructive comments on the manuscript. 


\section{Appendix}

List of the populations included in the analysis. For species, southern and northern limits of distribution range are given. For each population, stock name referring to ICES divisions, ICES fishing area, length of the time series (TS length), recruitment variability (varR), latitudinal position and index of standardized position in species range (pos) are given.

\begin{tabular}{|c|c|c|c|c|c|}
\hline Stock name & Fishing area & TSlength & $\operatorname{varR}$ & latitude & pos \\
\hline \multicolumn{6}{|c|}{ Anchovy (Engraulis encrasicolus) $30^{\circ} \mathrm{N}-60^{\circ} \mathrm{N}$} \\
\hline VIII a-b & Bay of Biscay & 15 & 0.122 & 45.5 & 0.03 \\
\hline \multicolumn{6}{|c|}{ Anglerfish (Lophius piscatorius) $20^{\circ} \mathrm{N}-7^{\circ} \mathrm{N}$} \\
\hline VIIIc IXa & Spain - Portugal & 14 & 0.027 & 40.25 & -0.15 \\
\hline VIIe-k VIIIa-b & B. Biscay - Celtic Sea & 14 & 0.006 & 49 & 0.13 \\
\hline \multicolumn{6}{|c|}{ Cod (Gadus morhua) $48^{\circ} \mathrm{N}-75^{\circ} \mathrm{N}$} \\
\hline VIIe-k & Celtic Sea & 30 & 0.181 & 51 & -0.78 \\
\hline VIIa & Irish Sea & 34 & 0.123 & 54 & -0.56 \\
\hline $21-24$ & Baltic Sea & 32 & 0.103 & 55 & -0.48 \\
\hline IIIa IV VIId & North Sea & 38 & 0.123 & 56 & -0.41 \\
\hline Kattegat & Kattegat & 30 & 0.089 & 58 & -0.26 \\
\hline $\mathrm{VIa}$ & West of Scotland & 36 & 0.123 & 58.5 & -0.22 \\
\hline $25-32$ & Baltic Sea & 35 & 0.019 & 59.75 & -0.13 \\
\hline Vb1 & Faroes & 40 & 0.072 & 62 & 0.04 \\
\hline $\mathrm{Va}$ & Iceland & 46 & 0.046 & 63 & 0.11 \\
\hline I \& II & Norway - Barents sea & 55 & 0.119 & 72 & 0.78 \\
\hline
\end{tabular}

Flounder (Platichthys flesus) $30^{\circ} \mathrm{N}-7^{\circ} \mathrm{N}$

\begin{tabular}{|c|c|c|c|c|c|}
\hline $24-25$ & Baltic Sea & 23 & 0.008 & 55.25 & 0.17 \\
\hline \multicolumn{6}{|c|}{ Horse Mackerel (Trachurus trachurus) $40^{\circ} \mathrm{S}-7^{\circ} \mathrm{N}$} \\
\hline VIIIc - IXa & Spain - Portugal & 15 & 0.027 & 40.25 & 0.42 \\
\hline \multicolumn{6}{|c|}{ Haddock (Melanogrammus aeglefinus) $43^{\circ} \mathrm{N}-75^{\circ} \mathrm{N}$} \\
\hline IV IIIa & North Sea & 38 & 0.311 & 55 & -0.25 \\
\hline VIa & West of Scotland & 36 & 0.427 & 57 & -0.13 \\
\hline VIb & Rockall & 16 & 0.108 & 57.25 & -0.11 \\
\hline $\mathrm{Vb}$ & Faeroes & 39 & 0.164 & 62 & 0.19 \\
\hline $\mathrm{Va}$ & Iceland & 18 & 0.181 & 65 & 0.38 \\
\hline I \& II & Norway - Barents sea & 51 & 0.334 & 71.5 & 0.78 \\
\hline \multicolumn{6}{|c|}{ European hake (Merluccius merluccius) $20^{\circ} \mathrm{N}-72^{\circ} \mathrm{N}$} \\
\hline Southern stock & Spain - Portugal & 19 & 0.004 & 40.25 & -0.22 \\
\hline Northern stock & Biscay - Celtic Sea & 22 & 0.008 & 51.5 & 0.21 \\
\hline \multicolumn{6}{|c|}{ Herring (Clupea harengus) $48^{\circ} \mathrm{N}-72^{\circ} \mathrm{N}$} \\
\hline$\overline{\mathrm{VIIj}}$ & Celtic Sea & 40 & 0.092 & 50 & -0.83 \\
\hline VIIa & Irish Sea & 29 & 0.056 & 54 & -0.50 \\
\hline VIa South & West of Scotland & 31 & 0.069 & 54.5 & -0.46 \\
\hline IV VIId IIIa & North Sea & 40 & 0.083 & 56 & -0.33 \\
\hline VIa North & West of Scotland & 25 & 0.080 & 57 & -0.25 \\
\hline $25-29 \& 32$ & Baltic Sea & 27 & 0.035 & 57 & -0.25 \\
\hline Gulf of Riga & Baltic Sea & 31 & 0.107 & 59.75 & -0.02 \\
\hline 30 & Baltic Sea & 21 & 0.051 & 62 & 0.17 \\
\hline $\mathrm{Va}$ & Iceland & 40 & 0.108 & 63 & 0.25 \\
\hline 31 & Baltic Sea & 21 & 0.176 & 64.5 & 0.38 \\
\hline I \& II & Norway - Barents sea & 69 & 0.427 & 70 & 0.83 \\
\hline
\end{tabular}

Four spot Megrim (Lepidorhombus boscii) $26^{\circ} \mathrm{N}-63^{\circ} \mathrm{N}$

\begin{tabular}{llllll}
\hline VIIIc - IXa & Spain - Portugal & 15 & 0.051 & 40.5 & -0.24 \\
\hline
\end{tabular}


Megrim (Lepidorhombus whiffiagonis) $26^{\circ} \mathrm{N}-64^{\circ} \mathrm{N}$

\begin{tabular}{|c|c|c|c|c|c|}
\hline VII - VIII & B. Biscay - Celtic Sea & 17 & 0.018 & 49 & 0.21 \\
\hline VIIIc - IXa & Spain - Portugal & 15 & 0.085 & 40.5 & -0.24 \\
\hline \multicolumn{6}{|c|}{ Norway pout (Trisopterus esmarkii) $48^{\circ} \mathrm{N}-7^{\circ} \mathrm{N}$} \\
\hline IV IIIa & North Sea & 27 & 0.135 & 55 & -0.44 \\
\hline \multicolumn{6}{|c|}{ Plaice (Pleuronectes platessa) $30^{\circ} \mathrm{N}-73^{\circ} \mathrm{N}$} \\
\hline VIIe & English Channel & 25 & 0.059 & 49.5 & -0.09 \\
\hline VIId & English Channel & 21 & 0.040 & 50 & -0.07 \\
\hline VIIf-g & Celtic Sea & 24 & 0.045 & 51 & -0.02 \\
\hline VIIa & Irish Sea & 37 & 0.020 & 54 & 0.12 \\
\hline IV & North Sea & 44 & 0.045 & 56 & 0.21 \\
\hline IIIa & Kattegat & 23 & 0.024 & 57 & 0.26 \\
\hline \multicolumn{6}{|c|}{ Saithe (Pollachius virens) $48^{\circ} \mathrm{N}-7^{\circ} \mathrm{N}$} \\
\hline IIIa IV VI & North Sea & 33 & 0.047 & 56 & -0.36 \\
\hline $\mathrm{Vb}$ & Faroes & 38 & 0.047 & 61.5 & 0.08 \\
\hline $\mathrm{Va}$ & Iceland & 37 & 0.039 & 65 & 0.36 \\
\hline I \& II & Norway - Barents sea & 41 & 0.074 & 71.5 & 0.88 \\
\hline
\end{tabular}

Sandeel (Ammodytes marinus) $49^{\circ} \mathrm{N}-74^{\circ} \mathrm{N}$

\begin{tabular}{llllll}
\hline IV & North sea & 18 & 0.190 & 56 & -0.52 \\
\hline
\end{tabular}

Sardine (Sardina pilchardus) $20^{\circ} \mathrm{N}-58^{\circ} \mathrm{N}$

\begin{tabular}{lccccc}
\hline VIIIc - IXa & Spain - Portugal & 22 & 0.055 & 40.25 & 0.07 \\
\hline Sole (Solea solea) $\mathbf{2 0}^{\circ} \mathbf{N} \mathbf{- ~}^{\circ} \mathbf{6 0}^{\circ} \mathbf{N}$ & & & & \\
\hline VIIIa-b & Bay of Biscay & 17 & 0.007 & 45.5 & 0.28 \\
VIIe & English Channel & 32 & 0.037 & 49.5 & 0.48 \\
VIId & English Channel & 19 & 0.057 & 50 & 0.50 \\
VIIf-g & Celtic Sea & 30 & 0.031 & 51 & 0.55 \\
VIIa & Irish Sea & 32 & 0.104 & 54 & 0.70 \\
IV & North Sea & 43 & 0.250 & 56 & 0.80 \\
IIIa & Kattegat & 17 & 0.061 & 57.5 & 0.88 \\
\hline
\end{tabular}

Sprat (Sprattus sprattus) $43^{\circ} \mathrm{N}-67^{\circ} \mathrm{N}$

\begin{tabular}{lccccc}
\hline Baltic Stock & Baltic Sea & 27 & 0.240 & 59 & 0.25 \\
\hline Whiting (Merlangius merlangus) & $\mathbf{4 5}^{\circ} \mathbf{N}-\mathbf{7 0}^{\circ} \mathbf{N}$ & & & & \\
\hline VII e-k & Celtic Sea & 22 & 0.075 & 51 & -0.52 \\
VIIa & Irish Sea & 21 & 0.065 & 54 & -0.28 \\
IV & North Sea & 41 & 0.069 & 56 & -0.12 \\
VIa & West of Scotland & 23 & 0.065 & 57 & -0.04 \\
\hline
\end{tabular}




\section{References}

Alheit, J., Hagen, E., 1997. Long-term climate forcing of European herring and sardine populations. Fish. Oceanogr. 6, 130-139.

Bakun, A., 1996. Patterns in the Ocean : Ocean Processes and Marine Population Dynamics. University of California Sea Grant, San Diego.

Beamish, R.J., McFarlane, G.A., King, J.R., 2000. Fisheries climatology : understanding the interannual and decadal scale processes that regulate British Columbia fish populations naturally. In: Parsons, T., Harrison, P. (Eds.) Fisheries oceanography : an integrative approach to fisheries ecology and management. Blacwell Science, Oxford, pp. 94-139.

Beaugrand, G., Brander, K.M., Lindley, J.A., Souissi, S., Reid, P.C., 2003. Plankton effect on cod recruitment in the north sea. Nature. 426, 661-664.

Beaugrand, G., Reid, P.C., Ibanez, F., Lindley, J.A., Edwards, M., 2002. Reorganization of North Atlantic Marine Copepod Biodiversity and Climate. Science. 296, 1692-1694.

Bradford, J.M., 1991. Effects of ageing errors on recruitment time series estimated from sequential population analysis. Can. J. Fish. Aquat. Sci. 48, 555-558.

Brander, K.M., 1992. A re-examination of the relationship between cod recruitment and Calanus finmarchicus in the North Sea. ICES. Mar. Sci. Symp. 195, 393-401.

Brander, K.M., 1995. The effect of temperature on growth of Atlantic cod (Gadus morhua L.). ICES. J. Mar. Sci. 52, 1-10.

Brander, K.M., 2000. Effects of environmental variability on growth and recruitment in cod (Gadus morhua) using a comparative approach. Oceanol. Acta. 23, 485-496.

Brander, K.M., 2005. Cod recruitment is strongly affected by climate when stock biomass is low. ICES. J. Mar. Sci. In press.

Brander, K.M., Blom, M.F., Borges, M.F., Erzini, K., Henderson, G., MacKenzie, B.R., Mendes, H., Ribeiro, J., Santos, A.M.P., Toresen, R., 2003. Changes in fish distribution in the eastern North Atlantic: Are we seeing a coherent response to changing temperature? ICES Mar Sci Symp. 219, 261-270.

Buch, E., Nielsen, M.H., Perdersen, S.A., 2002. Ecosystem variability and regime shift in west Greenland waters. Sci Counc Res Doc NAFO. 02/16.

Cook, R.M., Sinclair, A., Stefánsson, G., 1997. Potential collapse of North Sea cod stocks. Nature. 385, 521-522. 
Coulson, J.C., Whittaker, J.B., 1978. Ecology of Mooreland animals. In: Heal, O.W., Perkins, D.F. (Eds.) Ecological Studies 27. Production Ecology of British Moors and Montane Grasslands. Springer-Verlag., Berlin, pp. 52-93.

Cury, P., Roy, C., 1989. Optimal environmental window and pelagic fish recruitment success in upwelling areas. Can. J. Fish. Aquat. Sci. 46, 670-680.

Cushing, D.H., 1982. Climate and Fisheries. Academic Press, London.

Cushing, D.H., 1984. The gadoid outburst in the North Sea. J. Cons. Int. Explor. Mer. 41, 159166.

Cushing, D.H., 1990. Plankton production and year-class strength in fish populations : an update of the Match / Mismatch hypothesis. Adv. Mar. Biol. 26, 249-294.

Dickson, R.R., Brander, K.M., 1993. Effects of a changing windfield on cod stocks of the North Atlantic. Fish. Oceanogr. 2, 124-153.

Fisher, R.A., 1954. Statistical methods for research workers, 12th edition. Oliver and Boyd, Edinburgh.

Fogarty, M.J., Myers, R.A., Bowen, K.G., 2001. Recruitment of cod and haddock in the North Atlantic : a comparative analysis. ICES J Mar Sci. 58, 952-961.

Garrod, D.J., Colebrook, J.M., 1978. Biological effects of variability in the North Atlantic Ocean. Rapp. P.-v Réun. Cons. Int. Explor. mer. 13, 128-144.

Gaston, K.J., 1990. Patterns in the geographical ranges of species. Biol Rev Camb Philos Soc. $65,105-129$.

Hennemuth, R.C., Palmer, J.E., Brown, B.E., 1980. A statistical description of recruitment in eighteen selected fish stocks. J. Northwest. Atl. Fish. Soc. 1, 101-111.

Hjellvik, V., Godø, O.R., Tjøstheim, D., 2002. The measurement error in marine survey catches: the bottom trawl case. Fish. Bull. 100, 720-726.

Hjort, J., 1914. Fluctuations in the Great fisheries of northern Europe viewed in the light of biological research. Rapp. P.-v Réun. Cons. Int. Explor. mer. 20, 1-228.

Huffaker, C.B., Messenger, P.S., 1964. The concept and significance of natural control. In: Bach, P.D. (Ed.) Biological control of insect pest and weeds. Chapman \& Hall, London., pp. 74-117.

Klyashtorin, L.B., 1998. Long-term climate change and main commercial fish production in the Atlantic and Pacific. Fish. Res. 37, 115-125.

Koslow, J.A., 1984. Recruitment patterns in northwest Atlantic fish stocks. Can J Fish Aquat Sci. 41, 1722-1729. 
Kovtsova, M.V., Boitsov, V.D., 1995. Recruitment of the Barents sea plaice (Pleuronectes platessa L.). Neth. J. Sea Res. 34, 229-235.

Lambert, T.C., 1990. The effect of population structure on recruitment in herring. J. Cons. Int. Explor. Mer. 47, 249-255.

Lapointe, M.F., Peterman, R.M., MacCall, A.D., 1989. Trends in fishing mortality rate along with errors in natural mortality rate can cause spurious time trends in fish stock abundances estimated by virtual population analysis (VPA). Can. J. Fish. Aquat. Sci. 46, 2129-2139.

Lasker, R., 1975. Field criteria for the survival of anchovy larvae : the relation between inshore chlorophyll maximum layers and successful first feeding. Fish. Bull. 73, 453462.

Leggett, W.C., Frank, K.T., 1997. A comparative analysis of recruitment variability in North Atlantic flatfishes - Testing the species range hypothesis. J Sea Res. 37, 281-299.

Marteinsdottir, G., Thorarinsson, K., 1998. Improving the stock-recruitment relationship in Icelandic cod (Gadus morhua) by including age diversity of spawners. Can. J. Fish. Aquat. Sci. 55, 1372-1377.

Miller, J.M., Burke, J.S., Fitzhugh, G.R., 1991. Early life history patterns of Atlantic North American flatfish: Likely (and unlikely) factors controlling recruitment. Neth. J. Sea Res. 27, 261-275.

Myers, R.A., 1991. Recruitment variability and range of three fish species. Sci. Counc. Stud. NAFO. 16, 21-24.

Myers, R.A., 1998. When do environment-recruitment correlations work? Rev. Fish. Biol. Fish. 8, 285-305.

Myers, R.A., 2001. Stock and recruitment: generalizations about maximum reproductive rate, density dependence, and variability using meta-analytic approaches. ICES. J. Mar. Sci. 58, 937-951.

Myers, R.A., Barrowman, N.J., 1996. Is fish recruitment related to spawner abundance? Fish. Bull. 94, 707-724.

Parmesan, C., Yohe, G., 2003. A globally coherent fingerprint of climate change impacts across natural systems. Nature. 421, 37-42.

Pennington, M., Stromme, T., 1998. Surveys as a research tool for managing dynamics stocks. Fish Res. 37, 97-106.

Pepin, P., 1991. Effect of temperature and size on development, mortality, and survival rates of the pelagic early life history stages of marine fish. Can J Fish Aquat Sci. 48, 503-518. 
Philippart, C.J.M., Henderson, P.A., Johannessen, T., Rijnsdorp, A.D., Rogers, S.I., 1998. Latitudinal variation on fish recruits in Northwest Europe. J Sea Res. 39, 69-77.

Poulard, J.-C., Blanchard, F., 2004. Impact of climate change on the fish community structure of the eastern continental shelf of the Bay if Biscay. ICES Mar Sci Symp. In press.

Pyper, B.J., Peterman, R.M., 1998. Comparison of methods to account for autocorrelation in correlation analyses of fish data. Can J Fish Aquat Sci. 55, 2127-2140.

Quero, J.-C., Du Buit, M.-H., Vayne, J.-J., 1998. The records of tropical fishes and the warming of the European Atlantic waters. Oceanol Acta. 21, 345-351.

Restrepo, V.R., Powers, J.E., Turner, S.C., Hoenig, J.M., 1991. Using simulation to quantify uncertainty in sequential population analysis (SPA) and derived statistics, with application to the North Atlantic swordfish fishery. ICES-CM-1991/D:31.

Richards, O.W., Southwood, T.R.E., 1968. The abundance of insects : Introduction. In: Southwood, T.R.E. (Ed.) Insects abundance. Blackwell Scientific Publications, Oxford. pp. 1-7.

Rochet, M.-J., Trenkel, V.M., 2003. Which community indicators can measure the impact of fishing? A review and proposals. Can J Fish Aquat Sci. 60, 86-99.

Shepherd, J.G., Pope, P.G., Cousens, R.D., 1984. Variations in fish stocks and hypotheses concerning their links with climate. Rapp. P.-v Réun. Cons. Int. Explor. mer. 185, $255-$ 267.

Sinclair, M., 1988. Marine populations. An essay on population regulation and speciation. Washington Sea Grant, Seattle.

Southward, A.J., Hawkins, S.J., Burrows, M.T., 1995. Seventy years' observations of changes in distribution and abundance of zooplankton and intertidal organisms in the western English Channel in relation to rising sea temperature. J Therm Biol. 20, 127-155.

Stebbing, A.R.D., Turk, S.M.T., Wheeler, A., Clarke, K.R., 2002. Immigration of southern fish species to south-western England linked to warming of the North Atlantic (19602001). J Mar Biol Ass U K. 82, 177-180.

Trenkel, V.M., Pinnegar, J.K., Rochet, M.-J., Rackham, B.D., 2004. Different surveys provide similar pictures of trends in a marine fish community but not of individual fish populations. ICES J Mar Sci. 61, 351-362.

Whitehead, P.J.P., Bauchot, M.-L., Hureau, J.-C., Nielsen, J., Tortonese, E. (1989) Fishes of the North-eastern Atlantic and the Mediterranean. Part I, II an III. UNESCO, Paris. 


\section{Tables}

Table 1. Results of the tests of the SRH .

For the non parametric test, Spearman rank correlation between recruitment variability and absolute value of population position in species range $\left(r_{s}\right)$ is given and for the parametric test, the second $\left(\beta_{1}\right)$ and first $\left(\beta_{2}\right)$ order terms of the quadratic regression, $\alpha$, the linear coefficient of time series length influence (model 2 only) and the coefficient of determination $\left(R^{2}\right)$ are given, with levels of significance $(*=p<0.05 ; * *=p<0.01) . n$ is the number of populations included in the test.

\begin{tabular}{cc}
\hline $\begin{array}{c}\text { All } \\
\text { populations }\end{array}$ & $\begin{array}{c}\text { All except } \\
\text { haddock }\end{array}$ \\
\hline Non parametric test & \\
\hline$r_{s} \quad 0.27$ & $0.52^{*}$ \\
Parametric test & \\
\hline
\end{tabular}

Model $1: \operatorname{var} R=\beta_{1} \operatorname{pos}^{2}+\beta_{2}$ pos $+\gamma$

$\begin{array}{ll}\beta_{1}=0.16^{* *} & \beta_{1}=0.17^{* *} \\ \beta_{2}=0.00 & \beta_{2}=0.02 \\ R^{2}=0.14^{*} & R^{2}=0.27^{* *}\end{array}$

Model $2: \operatorname{varR}=\alpha$ TSlength $+\beta_{1}$ pos $^{2}+\beta_{2}$ pos $+\gamma$

\begin{tabular}{ll}
$\alpha=0.003^{* *}$ & $\alpha=0.002^{*}$ \\
$\beta_{1}=0.13^{* *}$ & $\beta_{1}=0.15^{* *}$ \\
$\beta_{2}=-0.01$ & $\beta_{2}=-0.02^{* *}$ \\
$R^{2}=0.23^{* *}$ & $R^{2}=0.34^{* *}$ \\
\hline 62 & 56
\end{tabular}


Table 2. Results of the non parametric and parametric (model 1) tests of the SRH for the 7 most representative species.

\begin{tabular}{|c|c|c|c|c|c|c|}
\hline \multirow[t]{2}{*}{ Species } & \multirow[t]{2}{*}{$\mathrm{n}$} & \multirow{2}{*}{$\begin{array}{c}\begin{array}{c}\text { non parametric } \\
\text { test }\end{array} \\
r_{s} \\
\end{array}$} & \multicolumn{4}{|c|}{$\begin{array}{c}\text { parametric test, model } 1: \\
\operatorname{varR}=\beta_{1} \operatorname{pos}^{2}+\beta_{2} \text { pos }+\gamma\end{array}$} \\
\hline & & & $\beta_{1}$ & $\beta_{2}$ & $R^{2}$ & \\
\hline cod & 10 & $0.82 *$ & $0.14 * *$ & -0.04 & 0.70 & $*$ \\
\hline haddock & 6 & 0.37 & 0.62 & -0.32 & 0.35 & \\
\hline herring & 11 & 0.24 & $0.27 * *$ & $0.17 * *$ & 0.92 & $* *$ \\
\hline plaice & 6 & -0.26 & 0.40 & -0.13 & 0.50 & \\
\hline saithe & 4 & 0.50 & 0.05 & -0.00 & 0.88 & \\
\hline sole & 7 & $0.79 *$ & 0.15 & 0.43 & 0.41 & \\
\hline whiting & 4 & 0.40 & 0.07 & 0.02 & 0.78 & \\
\hline
\end{tabular}




\section{Figure legends}

Figure 1. Hypothesized relationship between recruitment variability (black U shaped curve) and a) latitudinal position (vertical bars) of the populations for the 7 main species and b) indices of position in the standardised distribution range for the 62 populations. Species latitudinal distribution in a) are in light grey, with the part covered by the data in dark grey).

Figure 2. Range of variability in recruitment for the combined 62 populations and for each species.

Figure 3. Relationship between recruitment variability (varR) and standardized position in species range (pos), and regression curve (with 95\% confidence bounds) for the model 1 when haddock (depicted by triangles) is excluded. Symbol size is proportional to time series length.

Figure 4. Distribution of the probability of the test of significance on $\beta_{1}$ in the model 1 fitted for 1000 position datasets for different levels of uncertainty on the position index.

Figure 5. Relationship between recruitment variability and standardized position in species range and quadratic regression curves for the 7 main species. 


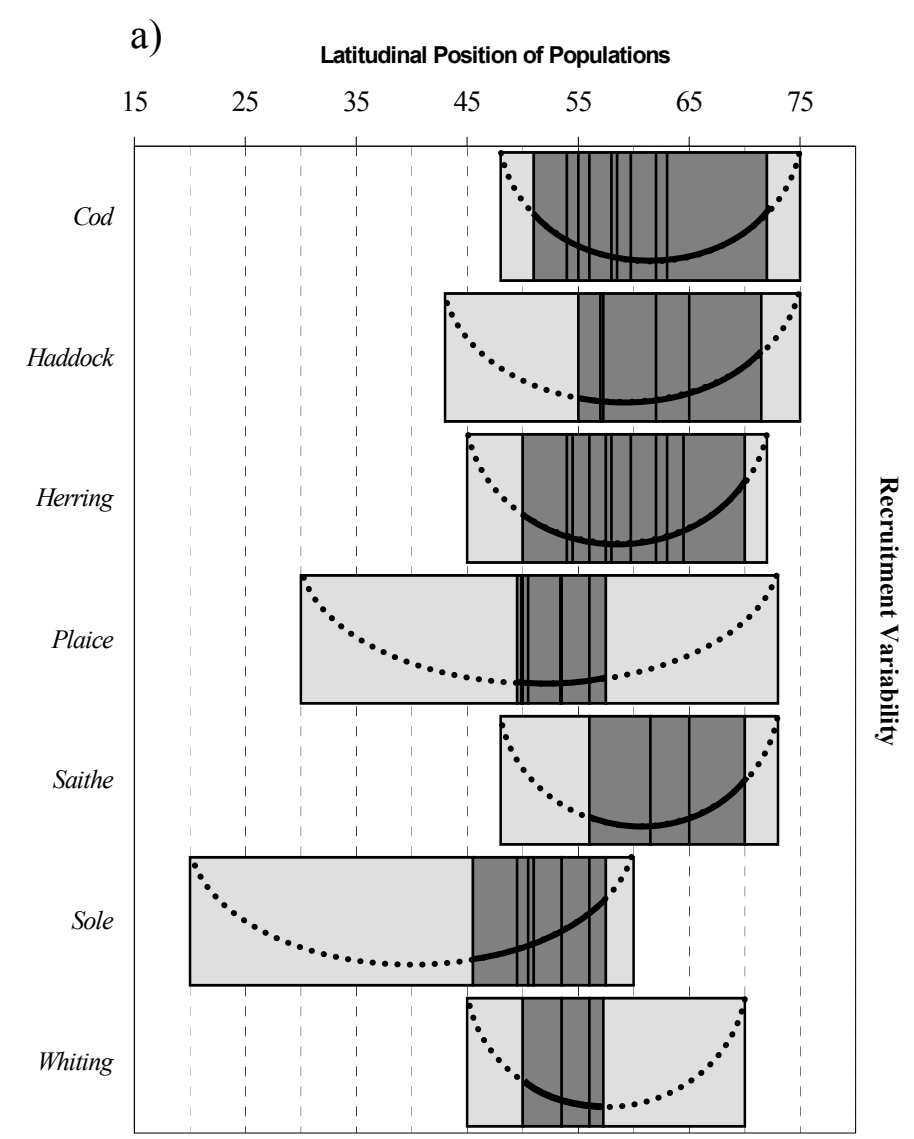

b)

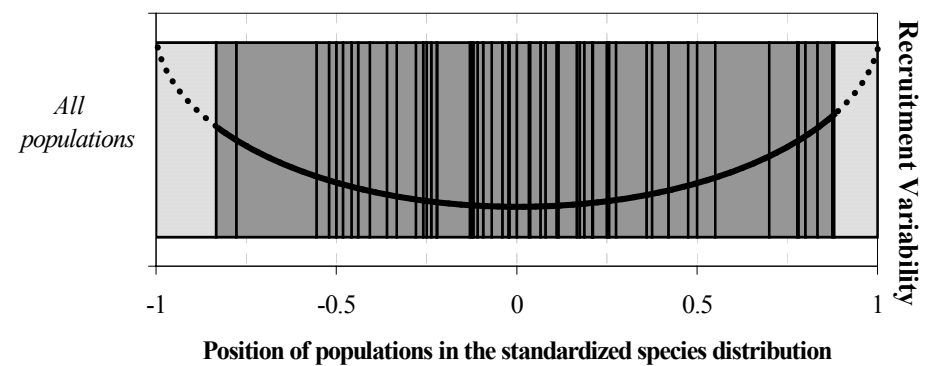

Figure 1 Brunel and Boucher 


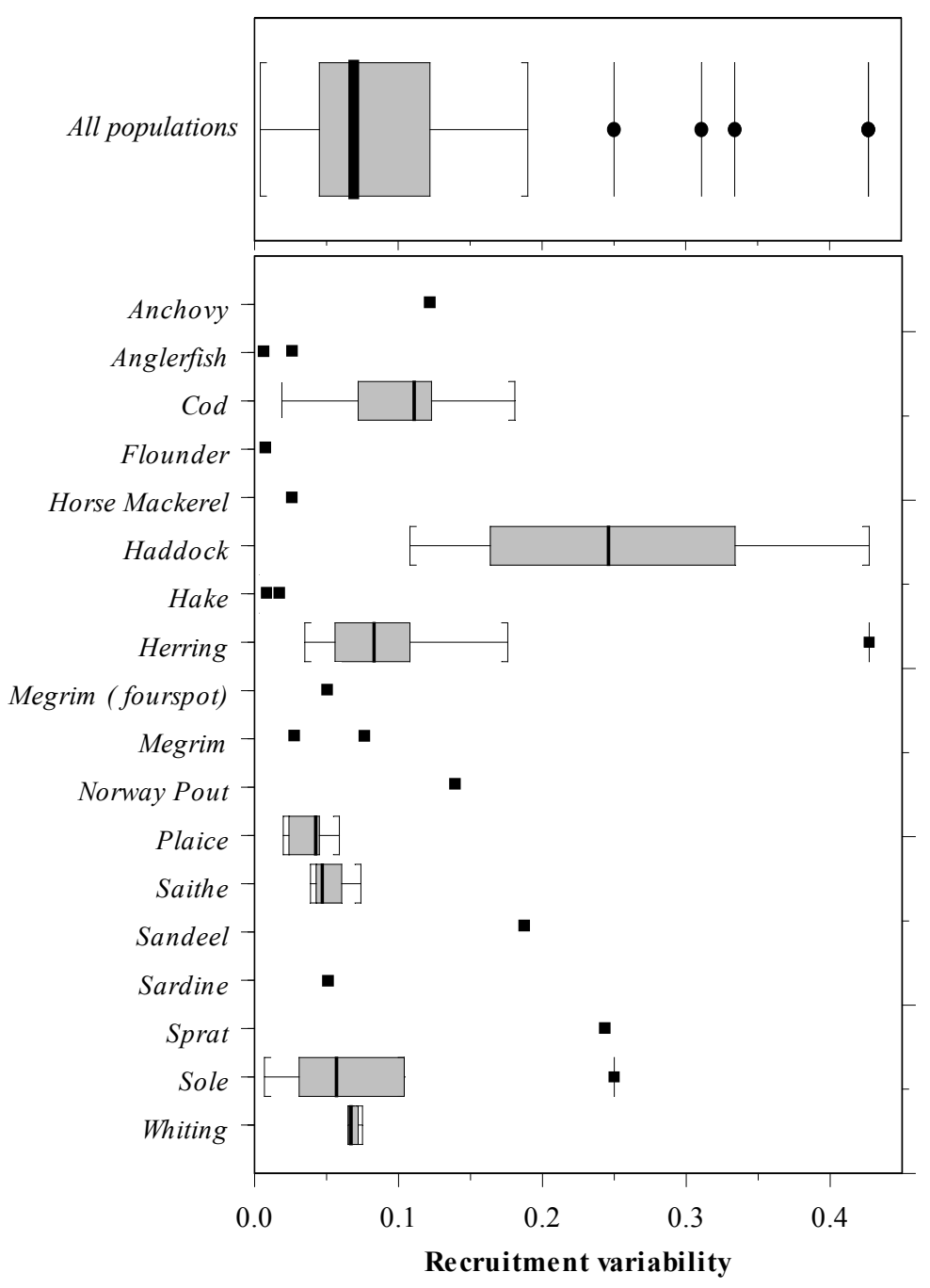

Figure 2 Brunel and Boucher 


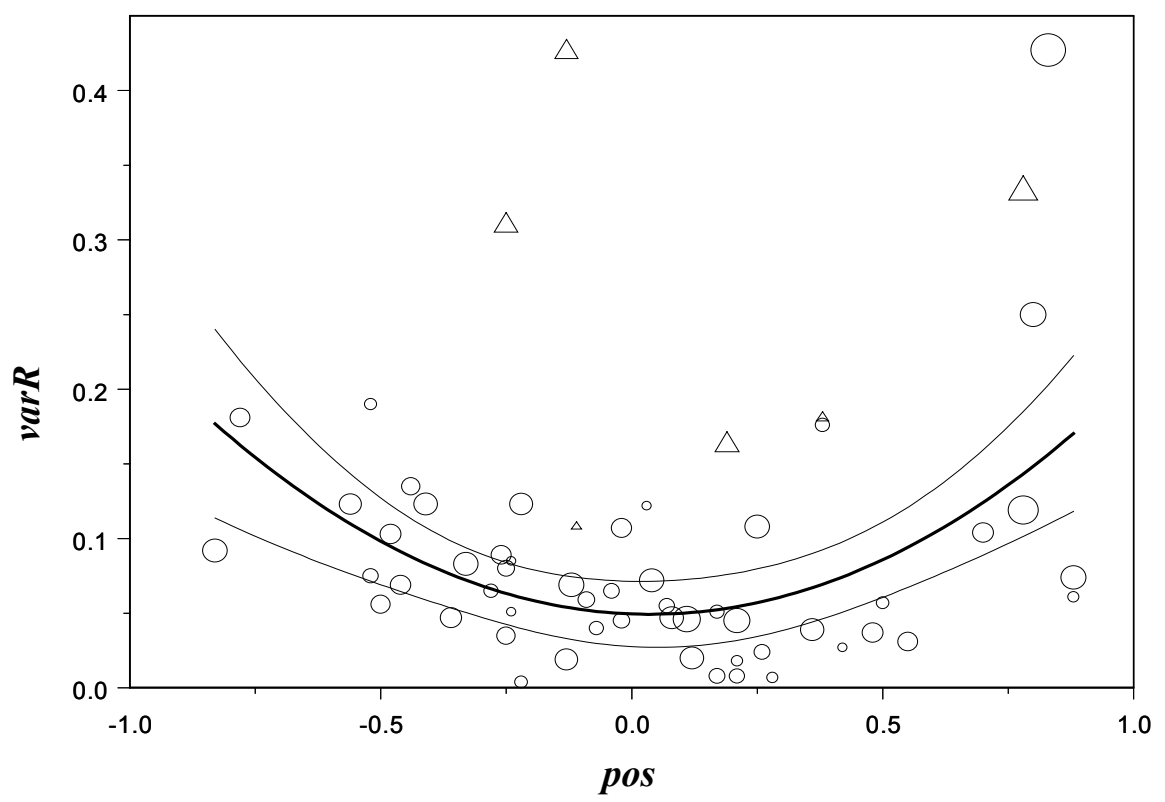

Figure 3 Brunel and Boucher 


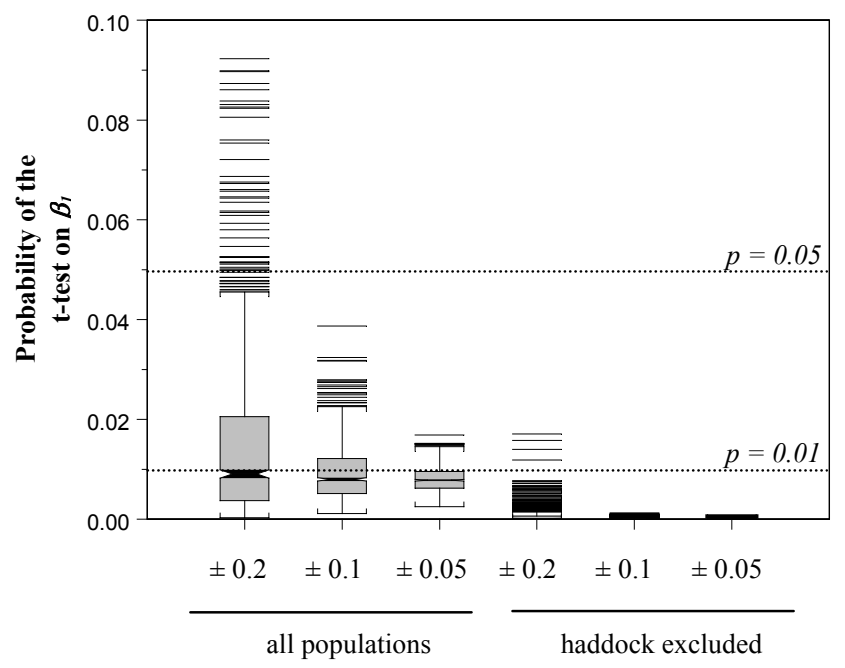

Levels of uncertainty on the position index

Figure 4 Brunel and Boucher 
a)

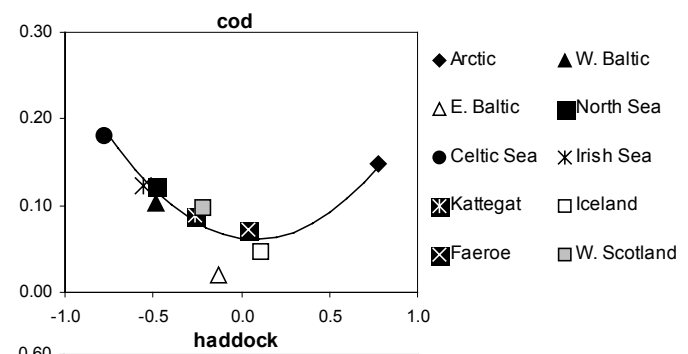

b)

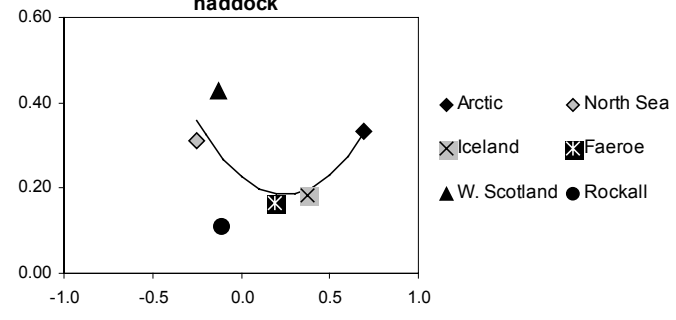

c)

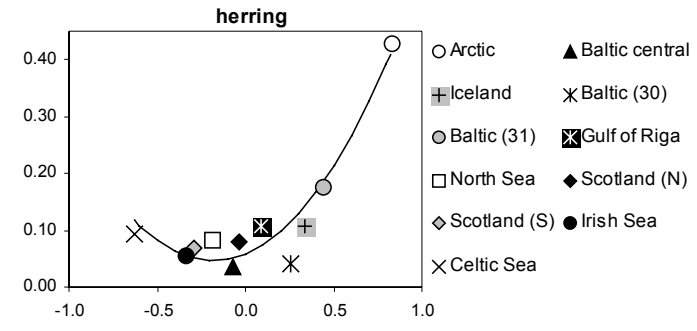

d)

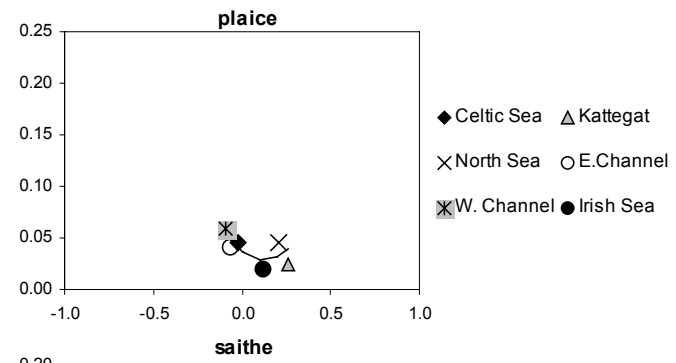

e)

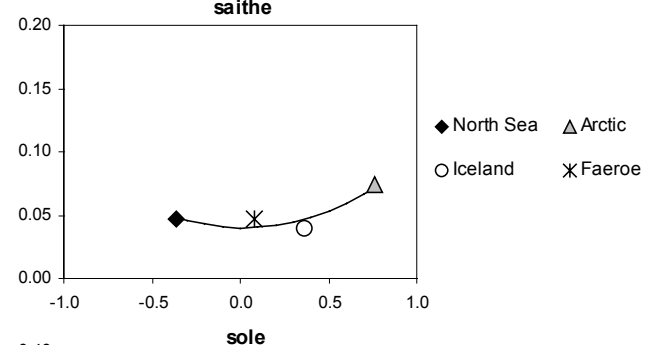

f)

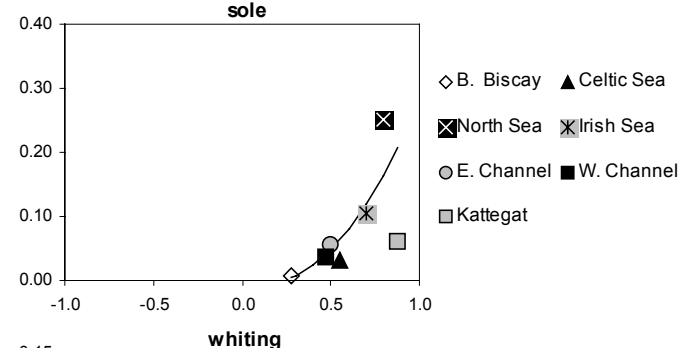

g)

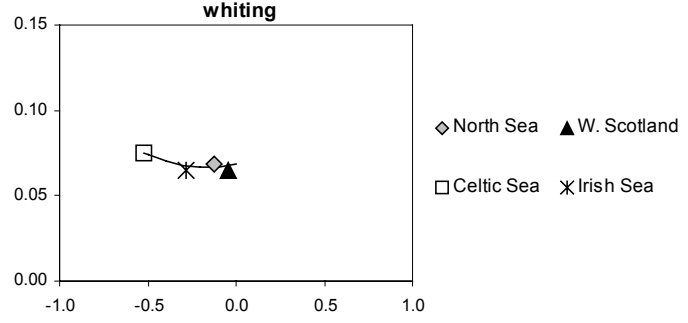

Figure 5 Brunel and Boucher 